\title{
UM RELATO DE EXPERIÊNCIA SOBRE A PREVENÇÃO CONTRA AS DROGAS POR MEIO DA EXTENSÃO NA UESB
}

\author{
Matheus Soura Campos Costa ${ }^{1}$ \\ Clándia Ferreira da Silva Luz² \\ Ana Lúcia Santos Souza
}

\section{RESUMO}

A Extensão é um dos pilares do Ensino Superior, em virtude da possibilidade de aproximação da universidade e sociedade, como também de produção de conhecimento entre extensionistas e o agrupamento social. Na extensão, é fundamental o trabalho de temáticas concernentes à realidade e às necessidades da população. As drogas incluem-se nesse viés, uma vez que afetam profundamente as camadas sociais, principalmente, os adolescentes e jovens, que representam o fragmento social mais suscetível ao consumo dessas substâncias. Diante da necessidade de atenuar esse problema, foi criado em 2011, na Universidade Estadual do Sudoeste da Bahia (UESB), o Projeto de Extensão "Drogas: conhecer para não usar - o ensino de biologia na prevenção", com suas atividades vinculadas ao Laboratório de Ensino de Biologia (LEBio). Esse projeto objetivou promover ações para prevenção

\footnotetext{
${ }^{1}$ Graduando em Odontologia e Monitor bolsista do Projeto de extensão "Drogas: conhecer para não usar - o Ensino de Biologia na prevenção" (financiado pela UESB). E-mail: teu91@hotmail.com 2 Professora do Departamento de Ciências Biológicas da UESB - Campus de Jequié e Coordenadora do Projeto de extensão "Drogas: conhecer para não usar - o Ensino de Biologia na prevenção" (Projeto financiado pela UESB). E-mail: cl.luz@hotmail.com

${ }^{3}$ Mestranda do Programa de Pós-graduação Mestrado em Educação Científica e Formação de Professores - DCB/UESB. E-mail: ubatense@yahoo.com.br
}

\begin{tabular}{l|l|l|l|l}
\hline Revista Extensão \& Cidadania & Vitória da Conquista & v. 1, n. 1 & p. 211-221 & jan./jun. 2013 \\
\hline
\end{tabular}


contra o uso de drogas, utilizando como lócus de ação o espaço escolar. As ações desse Projeto de Extensão foram realizadas por meio da utilização da metodologia participativa e problematizadora, que possibilitou as trocas e aquisições de conhecimento entre os integrantes do processo extensionista, alcançadas sem o estabelecimento de uma hierarquização, esta ainda muito presente no contexto universitário. Para que essa abordagem fosse efetivada, utilizou-se o formato das oficinas, nas quais diversos recursos foram empregados para que se alcançassem os objetivos propostos.

Palavras-chave: Drogas. Escolas públicas. Extensão. Prevenção.

\begin{abstract}
Extension is one of the pillars of university education, because of the possibility of narrow ties between the university and society, as well as production of knowledge between extensionists and social grouping. In extension, it is essential to work issues concerning the reality and needs of the population. The drugs are included in this bias, once profoundly affect social groups, especially teenagers and young people, who present the social fragment more susceptible to intake of these substances. Faced with the need to mitigate this problem, was created in 2011, at the State University of Southwest Bahia (UESB), the Extension Project "Drugs: know to use not - the teaching of biology at prevention," with its activities related to the Laboratory of the Teaching of Biology (LEBio). This project aims to promote measures for preventing drug use using as a locus of action the school space. The actions of this extension project are performed through the use of participatory and problematising methodology, enabling the exchange and acquisition of knowledge among members of the extension process which are achieved without the establishment of a hierarchy, still very present in the university context. For this approach to be effective, is used the format of the workshops, in which various features are used in order to achieve the proposed goals.
\end{abstract}

Keywords: Drugs. Public schools. Extension. Prevention.

\title{
Introdução
}

Por várias décadas as universidades vêm passando por um processo de evolução e, consequentemente, uma ressemantização de conceitos. De um espaço restrito a determinada classe social e, de 
certa forma, isolado de todo um agrupamento social, as instituições de Ensino Superior ganham, atualmente, novos rumos ao terem que responder a diversas demandas existentes na sociedade.

A Extensão, um dos pilares da universidade brasileira, assim como o ensino e a pesquisa, vem preencher lacunas existentes na sociedade, de modo a tornar acessíveis os conhecimentos científicos produzidos historicamente. Nesse sentido, a extensão acadêmica representa uma forma de democratização do conhecimento, além disso, possibilita estabelecer diálogos com a comunidade, facultando aos extensionistas a aquisição de conhecimentos em relação a situações antes desconhecidas.

A Constituição Federal de 1988, no seu artigo 207, estabelece a indissociabilidade entre a tríade Ensino-Pesquisa-Extensão. Já a Lei de Diretrizes e Bases (LDB), no artigo 43, define a finalidade da promoção da Extensão e os objetivos dessa prática. Fica claro no artigo supracitado, no inciso VI, que a Educação Superior tem por finalidade: "estimular o conhecimento dos problemas do mundo presente, em particular os nacionais e regionais, prestar serviços especializados à comunidade e estabelecer, com esta, uma relação de reciprocidade". Para complementar, o inciso VII acrescenta que esse tipo de ensino deve "promover a extensão, aberta à participação da população, visando à difusão das conquistas e benefícios resultantes da criação cultural e da pesquisa científica e tecnológica geradas na instituição" (BRASIL, 1996, p. 15).

O processo de produção de conhecimento pela pesquisa, na universidade, pode suscitar alguns projetos que visem intervir na realidade a fim de minimizar os problemas relacionados a toda coletividade ou a grupos populacionais. Assim, a extensão gera contribuições sociais, pela resolução ou minimização de fatos preocupantes.

O problema das drogas inclui-se nesse pressuposto por causa da sua magnitude e danos oriundos do consumo dessas substâncias. As primeiras experiências com drogas, em sua maioria, ocorrem na 
adolescência - período de transição entre a dependência dos pais e uma relativa autonomia, o qual é decisivo na formação da identidade do sujeito (ERIKSON, 1968). Por conseguinte, deve ser dada ênfase à execução de projetos de prevenção ao consumo de drogas, direcionados a esse segmento social inserido na faixa de risco.

Pensando num plano de ação conjunta, relacionado a esse assunto, foi criado em 2011, na Universidade Estadual do Sudoeste da Bahia (UESB), o projeto de extensão Drogas: conhecer para não usar - $O$ ensino da Biologia na prevenção, promovido pelo Laboratório de Ensino de Biologia (LEBio), com o apoio da Pró-Reitoria de Extensão e Assuntos Comunitários (PROEX), e efetivado com recursos dessa Universidade.

\section{A relevância de Projetos de Extensão sobre as drogas}

O consumo de drogas por adolescentes vem crescendo de forma assustadora. De acordo com um levantamento realizado pelo Centro Brasileiro de Informações sobre Drogas Psicotrópicas (CEBRID) entre 1987 e 1997, em várias capitais brasileiras, houve uma tendência alarmante do consumo de drogas entre adolescentes em idade escolar (GALDURÓZ et al., 2005). Assim, esse problema tem sido o centro das atenções para diversas áreas do conhecimento e setores da sociedade. A universidade não fica, então, como expectadora, ela vai a campo tentar estabelecer vínculos que auxiliem na prevenção de um problema que tem crescido de forma descontrolada.

Nesse sentido, ao promover o debate e a reflexão sobre as consequências do uso de drogas, a universidade pode favorecer a apreensão e troca de conhecimentos com a sociedade, minimizando o consumo dessas substâncias, pois a prevenção ainda é a melhor forma de combate ao uso de entorpecentes. Pensando nas estratégias para prevenção, estabelecidas pela Organização das Nações Unidas para a Educação, a Ciência e a Cultura (UNESCO) em 1970, a escola passou a ser considerado o melhor local para a abordagem preventiva (MOREIRA; SILVEIRA; ANDREOLI, 2006). 
Ao incluir a escola como espaço de conscientização e de promoção à saúde, esse projeto procurou proporcionar conhecimentos que possibilitassem ao educando fazer uma releitura das informações recebidas por intermédio dos meios de comunicação, da escola, da família e de sua própria vivência. A escola é um dos locais privilegiados na contribuição para o desenvolvimento de posturas e atitudes saudáveis na construção do comportamento dos indivíduos. Ao articular educação e saúde, possibilita-se em um só local (a escola), abranger indivíduos em fase de formação física, mental e social (SANMARTÍ, 1988).

De acordo com os Parâmetros Curriculares Nacionais (PCN), é necessária a implementação de temas transversais no Ensino Fundamental e Médio, com o objetivo de proporcionar a formação de atitudes que promovam a cidadania. A saúde, então, destaca-se como um viés para a aplicação da transversalidade. Assim, a saúde não deve ser abordada somente como a ausência de uma patologia e, em relação às drogas, não deveria enfatizar somente a dependência química. Contudo, a compreensão da repercussão da utilização dessas substâncias, em aspectos físico, psíquico e social, é considerada essencial para a formação de discentes-cidadãos. Tiba (1998) corrobora com esse pensamento ao afirmar que o processo de discussão dessa temática é contínuo e envolve a coletividade escolar, reafirmando a necessidade de uma prática educativa que facilite a informação atrelada à formação pessoal de cada aluno.

É na prevenção que a escola precisa agir. E é com esse intuito que o projeto atua; a universidade vai até a escola, por meio dos docentes e discentes, para propiciar reflexões sobre as consequências e as alterações provocadas pelo uso dessas substâncias, para preparar a comunidade escolar para as futuras escolhas, bem como, para contribuir com a compreensão dessa temática pouco discutida. Não há um modelo, uma fórmula, uma metodologia apropriada para abordar a questão das drogas. Tratar a diversidade de ideias sobre essa problemática de forma dinâmica, na sala de aula, é um caminho interessante para evitar 
os estigmas e preconceitos que emergem desse tema. A discussão das particularidades de cada realidade, criando formas diferenciadas de abordagem, permite estratégias mais duradouras e eficazes, que suscitam outros temas relacionados, como violência e desemprego, o que é essencial para a abordagem sobre a associação entre consumo de drogas e tecido social (DIAS, 2002).

\section{A extensão efetivada: atividades desenvolvidas pelo Projeto de Extensão Drogas: Conhecer para não usar}

Figura 1: Ludo - dinâmica com participação dos alunos.

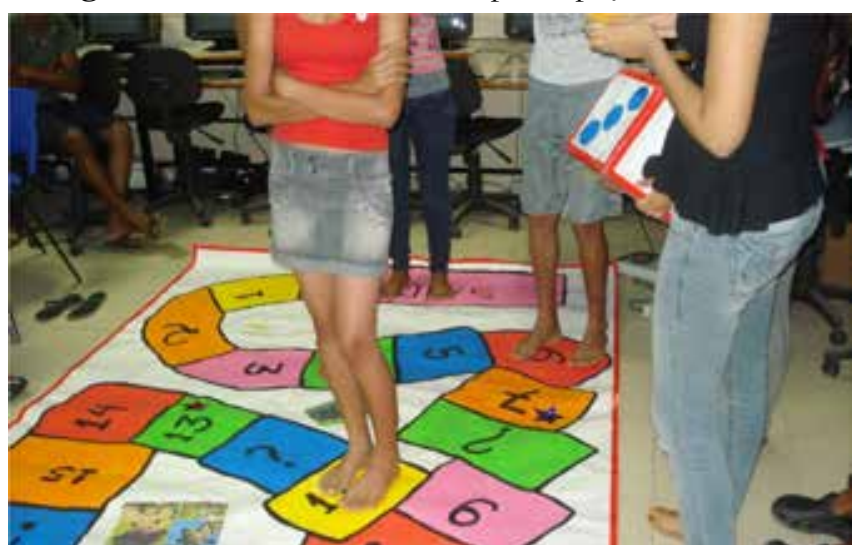

Fonte: Arquivos do Projeto de Extensão.

Com o objetivo de fazer uma abordagem diferenciada sobre a prevenção ao uso de drogas, foi utilizada uma metodologia participativa e problematizadora, com o intuito de suscitar a reflexão sobre os danos causados pelas substâncias químicas e ao mesmo tempo, despertar a vontade de mudar o quadro complexo das escolhas equivocadas que ocorrem cada vez mais precocemente. Desse modo, o projeto respeita as propostas conceituais de extensão, recomendadas por Freire (1983), a fim de não torná-las um simples processo de comunicação.

O projeto foi desenvolvido a partir da realização de oficinas, com diversas dinâmicas, para e com alunos da Rede Pública de Ensino. Essa escolha foi feita devido à capacidade inerente a esse método de levar 
os alunos a construírem o seu próprio arcabouço de conhecimento, coletivamente. "Oficina é um tempo e um espaço para aprendizagem; um processo ativo de transformação recíproca entre sujeito e objeto; um caminho com alternativas, com equilibrações que nos aproximam progressivamente do objeto a conhecer" (CUBERES, 1989, p. 3).

Figuras 2 e 3: Confecção e apresentação de cartazes relacionados à prevenção do uso de drogas (oficina 3).
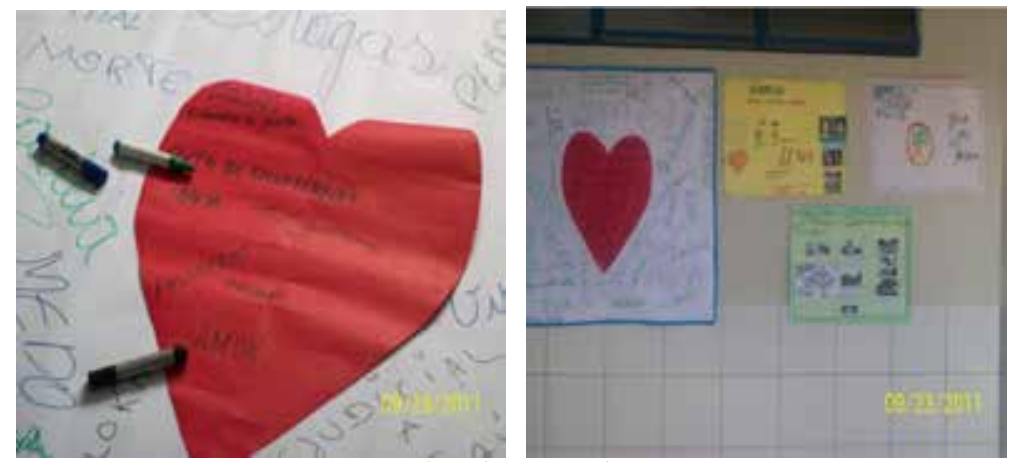

Fonte: Arquivos do Projeto de Extensão.

Também é objetivo dessas oficinas desmistificar algumas informações transmitidas pelos meios de comunicação ou em conversas informais entre colegas, para que os participantes do projeto façam escolhas coerentes com uma vida saudável e se tornem multiplicadores dessas ideias nas salas de aula, durante o ano letivo corrente e anos posteriores.

Nas oficinas, surgiu uma nova forma de comunicação, em que extensionistas e participantes contribuíram de acordo com suas vivências. Assim, essa produção de conhecimentos pôde ser concretizada ativamente pelos parceiros das oficinas, sem que houvesse uma invasão cultural por parte dos extensionistas, respeitando, assim, a visão de mundo dos alunos.

Vários foram os meios que serviram de subsídio para a abordagem da temática: vídeos, músicas, textos, dinâmicas, jogos, brincadeiras, produções artísticas, narração de histórias e outras 
atividades que permitiram a sensibilização dos adolescentes, com o intuito de despertar reflexões acerca dos danos causados pelas drogas.

Nessas oficinas, discutiu-se sobre os diferentes tipos de drogas e a infinitude de efeitos fisiológicos decorrentes do consumo dessas substâncias. Foram enfatizados os diferentes grupos de drogas e as modificações decorrentes delas na atividade do cérebro. Utilizou-se com frequência referenciais teóricos de pesquisadores como Cuberes (1989), Dias (2002), Galduróz et al. (2005), Moreira; Silveira e Andreoli (2006), Tiba (1998) e Castelões (2002), que trabalham com esse tema. Um deles apresenta as consequências fisiológicas das drogas a depender do tipo:

As depressoras da atividade do SNC são as que diminuem a atividade do cérebro, deixando o indivíduo "desligado". As substâncias que aumentam a atividade do cérebro, ou seja, estimulam o funcionamento fazendo com a pessoa fique "ligada", "elétrica" são as estimulantes do SNC. O terceiro grupo é constituído pelas drogas que agem modificando qualitativamente a atividade do cérebro: as perturbadoras (CASTELÕES, 2002).

Figuras 4 e 5: Produções nas oficinas 1 e 2.

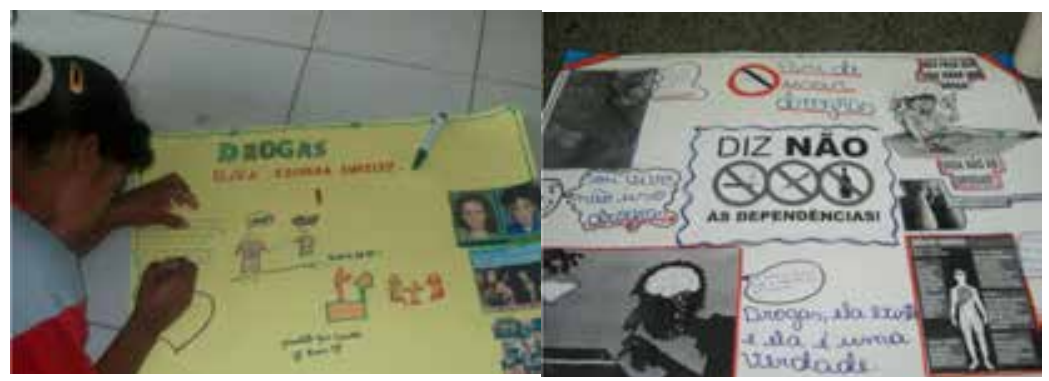

Fonte: Arquivos do Projeto de Extensão.

Há também uma preocupação em diferenciar as formas de consumo de drogas, geralmente, classificadas em uso, abuso e dependência química, termos estes, muitas vezes, utilizados como sinônimos, entretanto, possuem significações próprias. O uso é o consumo 
esporádico de determinada droga. O abuso é o consumo excessivo que irá repercutir patologicamente no indivíduo e induzir à dependência química. A dependência química é o resultado do aumento da tolerância (o corpo do indivíduo adapta-se à ação das drogas), fazendo com que sejam alcançadas as sensações da dose inicial somente quando há consumo de altas doses da droga.

Figura 6: Oficina realizada no laboratório (UESB - Jequié).

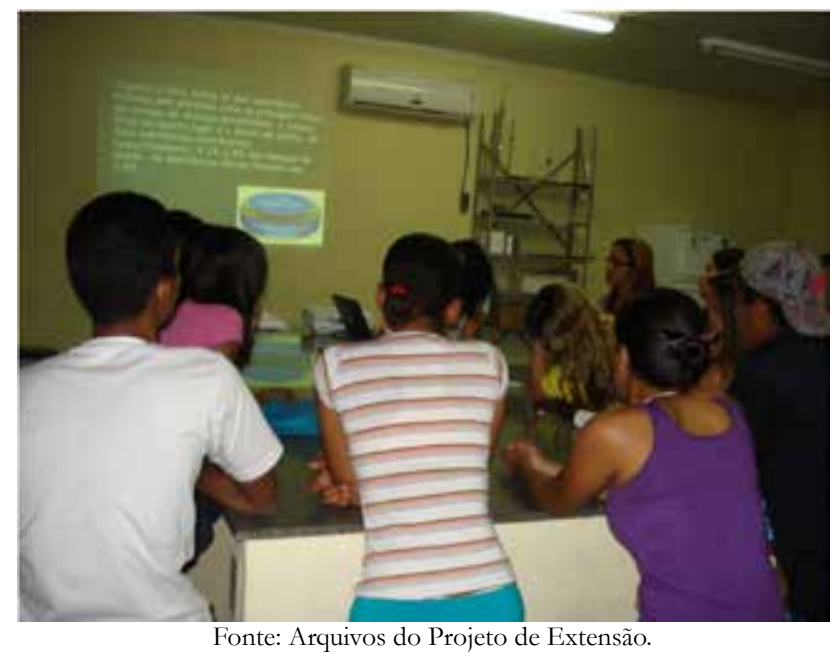

A maior parte das oficinas foi realizada nas próprias instituições de ensino às quais os alunos estão vinculados. Contudo, algumas oficinas foram realizadas nas dependências da UESB, com o mesmo grupo de alunos, alcançando um resultado satisfatório, principalmente, no que diz respeito à dinâmica estabelecida e à presença dos alunos. Nessas oficinas ocorreu a elaboração de diversos murais, cartazes e painéis - confeccionados pelos alunos e pelos extensionistas - que, após o término das atividades, retrataram toda a aprendizagem obtida mediante diálogo estabelecido entre eles. Assim, foi possível demonstrar a adequação das oficinas aos pressupostos da prática extensionista, por meio de uma via de mão dupla, representativa do trânsito de saberes entre a universidade e a sociedade. 


\section{Considerações Finais}

Constatou-se, portanto, a importância da Extensão Universitária na conjuntura social. Debater assuntos inerentes a toda sociedade é uma função primordial do Ensino Superior, desde que respeite a orientação ideológica de todos os envolvidos nesse processo. Diante disso, é notória a fidelidade do projeto de extensão Drogas: conhecer para não usar - $\mathrm{O}$ ensino da Biologia na prevenção aos princípios que norteiam suas ações, pois demonstrou uma importante função e resultados significativos no contexto local, apesar da complexidade da temática trabalhada e das repercussões oriundas do consumo dessas substâncias.

Observaram-se, ainda, os resultados decorrentes da adoção de uma metodologia participativa e problematizadora. A atuação do Projeto de Extensão, por intermédio de oficinas, tornou possível, até o momento, a realização do que foi idealizado para a execução desse projeto, o que possibilitou, também, a produção de conhecimentos de forma ativa e participativa.

\section{Referências}

BRASIL. Constituição da República Federativa do Brasil. Brasília: Senado Federal, Centro Gráfico, 1988.

. $L D B$ - Leis de Diretrizes e Bases da Educação Nacional. LEI No. 9.394, de 20 de dezembro de 1996.

. Ministério da Educação. Secretaria de Educação Fundamental. Parâmetros Curriculares Nacionais. Introdução. Brasília: MEC/SEF, 1997.

- Ministério da Educação. Parâmetros Curriculares Nacionais: Tema Transversal - saúde. Secretaria de Educação Fundamental. Brasilia: MEC/SEF, 1997.

CASTELÕES, Liliane. Drogas: brasileiros são mais dependentes em álcool, tabaco e maconha. 2002. Disponível em: <http://www.comciencia.br/ especial/drogas/drogas01.htm>. Acesso em: 19 set. 2011. 
CUBERES, M. T. G. El taller de lostalleres. Buenos Aires: Estrada, 1989. DIAS, S. Drogas: como abordar a questão das drogas na escola? 2002. Disponível em: <http://www.comciencia.br/especial/drogas/ drogas02.htm>. Acesso em: 19 set. 2011.

ERIKSON, E. Identity: Youth and Crisis. New York: Norton, 1968.

FREIRE, P. Extensão ou comunicação? Rio de Janeiro: Paz e Terra, 1983.

GALDURÓZ, J. C. F.; NOTO, A. R.; FONSECA, A. M.; CARLINI, E. A. $V$ levantamento nacional sobre o consumo de drogas psicotrópicas entre estudantes do ensino fundamental e médio da rede pública de ensino nas 27 capitais brasileiras: 2004. São Paulo: Centro Brasileiro de Informações sobre Drogas Psicotrópicas, Universidade Federal de São Paulo, 2005.

MOREIRA, F. G.; SILVEIRA, D. X. da; ANDREOLI, S. B. Redução de danos do uso indevido de drogas no contexto da escola promotora de saúde. Ciência \& Saúde Coletiva, v. 11, n. 3, p. 807-816, 2006.

SANMARTÍ, L. Educación sanitária: princípios, métodos e aplicaciones. Madrid: Diaz de Santos, 1988.

TIBA, I. Saiba mais sobre maconha e jovens: um guia para leigos e interessados no assunto. São Paulo: Agora, 1998. 